\title{
Editorial
}

\section{A NECESSIDADE DE PESQUISAS}

A medida em que melhor vão se tornando conhecidos os parâmetros do exercício da sexualidade, mais vai ficando clara a necessidade de que se regionalizem esses conhecimentos, tendo-se em vista a multiplicidade e a variedade de facetas encontradas. Assim, mostra-se cada vez menos adequado o emprego, em trabalhos nacionais, de dados advindos de pesquisas realizadas em outros países, com diferentes características populacionais e em meios socio-culturais diversos.

Por isso, a Diretoria da SOCIEDADE BRASILEIRA DE SEXUALI$D A D E$ HUMANA resolveu empreitar uma série de pesquisas que possam dizer aos profissionais brasileiros qual a nossa realidade atual. A intenção é de que se formem amplos bancos de dados, com informações diversificadas, que fiquem à disposição dos pesquisadores interessados.

A primeira dessas pesquisas já está em andamento e diz respeito as condições de iniciação sexual. Nossa intenção é que seja inquirido grande número de pessoas de diferentes faixas etárias e de todos os níveis sociais, além de - evidentemente - todos os associados da SBRASH. Ao receber este exemplar da Revista o leitor já deve ter recebido (e respondido, esperamos) o questionário que integra a fase inicial da pesquisa. Solicitamos a todos os nossos associados que colaborem com a Diretoria, divulgando cópias do questionário e conseguindo o maior número possível de respostas, para que os resultados sejam os mais confiáveis.

Outra iniciativa no mesmo sentido que estamos tomando diz respeito a constituição de uma Biblioteca básica sobre sexualidade humana, contendo obras representativas de tudo o que já se escreveu e se está escrevendo a respeito do assunto, no Brasil e no exterior. As obras de tal biblioteca ficarão, em breve futuro, ao dispor de nossos associados, através do uso de sistema informatizado, já em fase de implantação. Para a constituição de nossa Biblioteca estamos solicitando aos associados que doem livros, de sua autoria ou de terceiros, que podem ser enviados a Sede da SBRASH.

Esperamos, em breve, contar com um serviço de informações em sexualidade que possa prestar valiosos serviços aos nossos associados. Para isso, evidentemente. sua colaboração é extremamente necessária. 